\title{
Role of Whatsapp as a Teaching Aid to Enhance Learning Capabilities of Management Students
}

Pooja S Kushwaha* and Nidhi Jhawart

\begin{abstract}
The liberalising of Business Education in 1990 by the Indian Government has resulted in a large number of management schools offering management courses at graduate and post graduate levels. In the last five years, the number of B-school seats has grown three times. Excluding the few top B-schools like IIMs, most of the Bschools in the country are churning "unemployable" graduates. The paper uses convenience sampling to collect data from students and faculty members of different B-schools in order to find out their usage of digital technologies like Whatsapp for teaching and learning. It also explains the use of digital technology in curriculum designing. This further helps them in placing students in good profiles and better packages as they are able to share more practical real time insights with them.
\end{abstract}

Keywords: Liberalisation, ASSOCHAM, Unemployable, Digital technology, Whatsapp, B-schools, Pedagogy

\section{Introduction}

Nowadays, some B-schools are doing tremendous work for student employability readiness training in order to get respectable profiles and packages during institute placements. Awareness about the latest information technology concepts is one of the vital

\footnotetext{
* Jaipuria Institute of Management, Indore, India; pooja.singh@jaipuria.ac.in † IBMR, IPS Academy, Indore; India; nidhijhawar@ipsacademy.org
} 
parameters in getting good placements. According to India Today dated November 2015, the knowledge of technology would lead to good placements in IT and ITES companies. Internet, e-commerce, and technology companies like Amazon, OlaCabs, OYO rooms, Myntra and Uber were in the list of major recruiters in top B-school campus placements.

Students are aware that technology is now easily available on their phones. Due to stiff competition in the market, smartphones are available at affordable prices. It was assumed that by the end of 2017, every third citizen of the world would be using a smartphone. India is also growing in terms of its mobile users. Indian smartphone users have crossed 300 million and continued to grow annually by 18 percent in 2016 while the global smartphone market grew only by three percent.

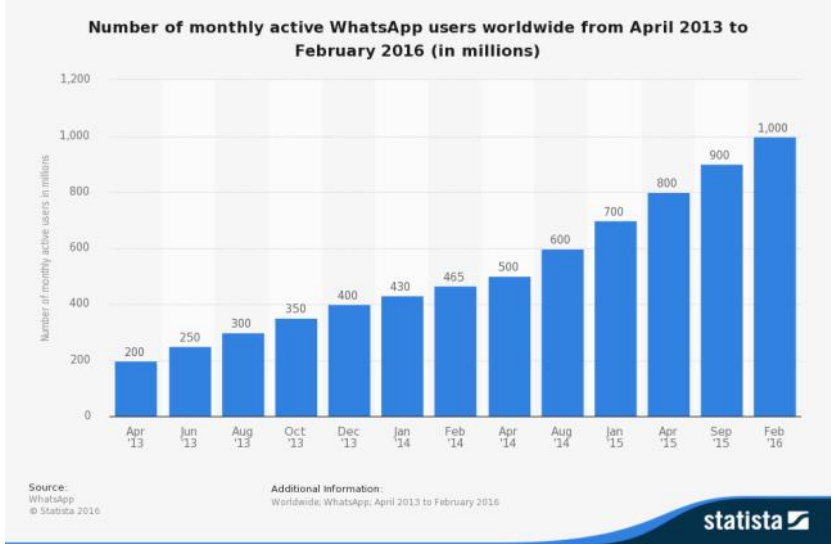

Fig 1 Growth of Whatsapp users from 2013 to 2016 (Statista, 2016)

Demonetisation popularised the prevailing new payment methods like Paytm, Airtel money and so forth to a large extent. This further contributed to the increasing demand of smartphones in India. The necessity of smartphones resulted in the further growth of sales of smartphones in 2017.

Technology is growing tremendously and life without it cannot be imagined. With an increased smartphone penetration in developing countries, internet based messaging is gradually overpowering the text based SMS. There are many web based messenger applications available like Hike, We Chat, Telegram and 
so on. However, Whatsapp has governed the market because of its simplistic features and 'easy to use' tag.

Whatsapp is considered a cross platform messaging tool as it works well with all mobile operating systems like iPhone, Windows, Android and so forth. Nowadays, it is treated as a very important tool of communication. In the recent past, it has been observed that Whatsapp has been an integral part of a youth's life. According to Forrester Research "Mobile Messaging Apps' Usage and Engagement", smartphone owners are profusely using different messenger apps like WeChat, Facebook messenger and Whatsapp. Whatsapp is being used primarily by management students not only for routine communication with their friends but also for academics.

Whatsapp allows the facility of creating groups with upto 256 contacts to whom messages can be sent at the same time in the form of texts, videos or audios. Students create groups through which they can share ideas, information, expressions and emotions. Research has been carried out on the impact of Whatsapp usage on academics which indicates a positive relationship between the usage and academic achievement. It also suggests a possibility of using it as a prominent tool for teaching in future (Roman, 2016).

\section{Review of literature}

Whatsapp is not only an application but also a communication medium which highlights a sense of belongingness and understanding with near and dear ones. Currently, Whatsapp is being used more often by the youth for exchanging information (Sharma, 2016).

Learning based on Whatsapp has a positive impact on the achievements of students. Students prefer innovative mobile based learning to conventional face to face teaching methodology (Amry, 2014). However, Whatsapp consumes much time resulting in procrastination, negative impact on students' spellings, grammatical and sentence framing and so forth. It also tends to distract students during classroom lectures and home assignments (Yeboah, 2014). 
There are mixed views regarding the usage of social networking apps like Whatsapp. It could negatively affect the future in terms of the education of Indian teenagers and children. Parents are strongly being recommended to check the mobile activities of teenagers on social media websites and prevent the use of social networking websites. International agencies and the Government should also take charge to ban these apps and sites (Kavita, 2015).

However, it has a positive influence on student learning. There are various academic advantages like accessibility of learning materials at any point in time, no time restriction of teachers' availability, learning beyond class hours and so forth (Bouhnik, 2014). Messaging services like Whatsapp are growing more quickly in some parts of the globe among the youth as compared to the other platforms like Facebook. (Mefolere, 2016).

The youth is using Whatsapp as a communication medium to exchange images, audio and video files with their friends. It has been proved that when they are idle and spend their time on smartphones, they access only Whatsapp (Jisha, 2014). The youth has shown positive perception and has accepted the use of Whatsapp for teaching and learning. However, they harbour an apprehension of receiving reading materials and questions after school hours as it might affect their personal lives (So, 2016).

Whatsapp is interesting and educationally useful. Students found that their increased interaction with peers and teachers positively affected their collaborative learning. However, the married students preferred the traditional classroom learning as they found Whatsapp disturbing their family time (Joshi, 2014). M-learning would become much easier and comfortable with Whatsapp (Mohesh, 2016). Use of the Whatsapp instant messaging helped students in learning mathematics. It developed a constructive environment for students to learn and improve their performance in mathematics (Kopung, 2016).

Facebook and Whatsapp group can be used as pedagogical tools for sending announcements, sharing resources, and initiating online discussions. The role of the admin is very crucial for moderating participation in the group (Susilo, 2014). Adequate research has been done in the area of using Whatsapp messenger 
for the purpose of academics. Many researchers have proved that the Whatsapp messenger has a positive impact on learning in schools as well as in higher education institutions. Due to 'anytime availability of instructor' as well as information in all forms like text, audio and video, it results in collaboration based learning.

Nascent empirical work is being done on the usage of Whatsapp and its impact on students' placements in B-schools. This study tries to explain empirically the impact of Whatsapp on students' placements from the perspective of the students, training as well as the placements department.

\section{Purpose of the study}

The study explains the usage of Whatsapp not only for information sharing but also for learning which helps students get good profiles and packages. The study among other things, discloses different facets of placements like 'easy to share' job description, sharing student anxieties, sharing interview issues and so forth. It also highlights how connectivity would help them get answers to queries from faculty members and how transparency between students as well as training and the placement department would lead to student satisfaction.

\section{Research methodology}

We have taken into account Theory of Planned Behaviour and the Technology Acceptance model for studying the conceptual framework. Davis (1995) proposes the Theory of Acceptance Model where he explains the three factors: Perceived Ease of Use, Perceived Usefulness and attitude towards using the system. According to him, attitude towards using the system is the main factor which determines whether the user would use or reject the system. The attitude towards the use is influenced by two major factors namely Perceived Ease of Use and Perceived Usefulness. According to Lee, Konzar and Larson (1985), TAM is so popular that it has been cited in most of the IS accepted researches. Davis, Bagozzi and Warshaw (1989) included behavioural intention as they felt people must have a strong behaviour intention to use the 
system which is above Perceived Usefulness and Ease of Use. This in turn would lead to a modified version of TAM.

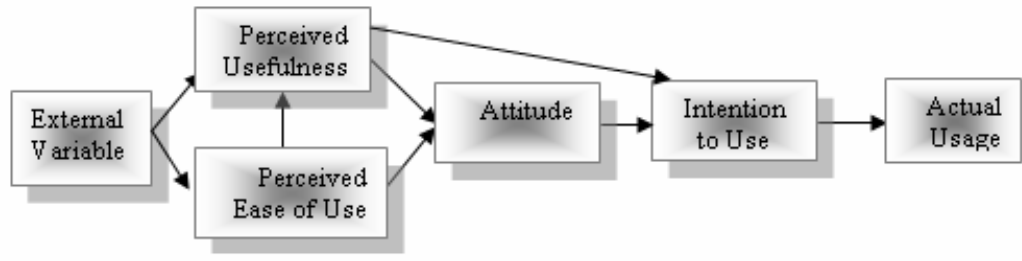

Fig 2 First modified version of TAM (Davis, Bagozzi \& Warshaw 1989, p. 985)

Venkatesh, Davis (1996) concluded that Perceived Usefulness and Perceived Ease of Use have a direct impact on behavioural intention. Therefore, they argued for discarding the attitude construct. After the amendment, the resultant model is shown in figure 3 .

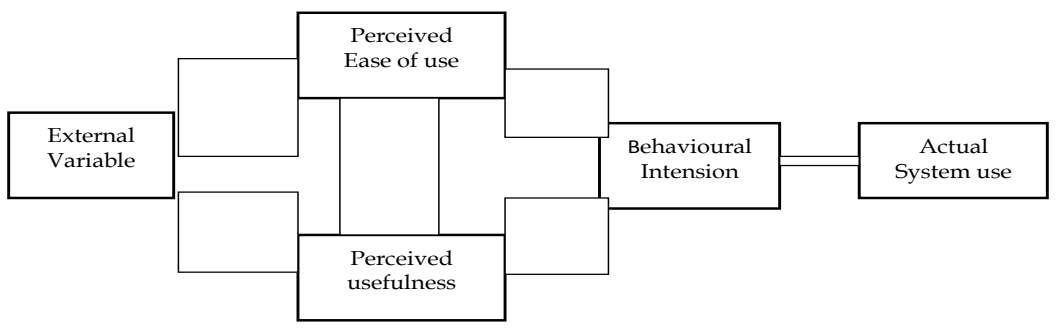

Fig 3 Ven katesh, Davis (1996)

Lee, Konzar and Larsen (2003) shared the limitations of the TAM model as they have used students as participants in a controlled environment. Yang and Yoo (2003) replicated the TAM model by adding two variables for attitude namely 'affective' and 'cognitive'. After statistical data analysis, they concluded that cognitive has statistical significance but affective does not. Chuttur (2009) stated that Technology Acceptance Model has been the only model to capture the most attention of the Information Systems community.

The author provides a historical overview of the Technology Acceptance Model (TAM) by briefing the evolution of TAM, its applications, limitations, and criticisms from various published articles. Data for this research was collected through a questionnaire. Three hundred final year management students 
from four different campuses of B-schools and 100 faculty members of the same B-schools were given the questionnaire. We were able to get 250 completely filled questionnaires from students and 50 from faculty members.

The purpose of the survey was to develop empirical evidence on the different factors important to utilise digital technologies like Whatsapp for teaching and learning by students and faculty member of B-schools. The survey was intended to determine:

- personal information (gender, age, academic discipline)

- respondents' use of Whatsapp (frequency and purpose of use)

- learning (area)

\section{Frequency of Whatsapp usage}

Digital networking applications are attracting youth and they spend most of their time on smartphones, using digital technology applications like Whatsapp. We have measured the frequency of Whatsapp usage of youth. There is a significant relationship among differential variables like "frequency of Whatsapp usage" and the other variables, i.e. time of WhatsApp usage: using at any time (37.1\%); using anywhere (44.0\%); text messaging (37.0\%); voice chat for 90 minutes a day (57.2\%); friends $50(40.9 \%)$ and (39.1\%) have 100 friends; use internet on Whatsapp around 120 minutes per day $(43.1 \%)$. Thus the overall results have significant chi-square variable (.000)

\subsection{Learning (Area)}

Digital networking applications are used by youth not only for entertainment or communication but also for learning. Researchers have measured percentage contribution by different respondents on different learning areas: current affair discussion with friends (25\%); job information sharing (70\%); interview questions sharing (40\%); group discussion topics sharing (35\%). 


\section{Findings of the study}

As per the data collected from the questionnaire, more than $80 \%$ of respondents using Whatsapp for teaching and learning had both good and bad experiences with B-schools but a majority of them were satisfied with the placement information shared through Whatsapp groups. While $75 \%$ students felt that since information was available any time, they could prepare well in time for their examinations by getting their doubts cleared, $25 \%$ had a bad experience due to Whatsapp groups which were not controlled by the admin. The negative messages shared by students in the group created negative assumptions for that subject or company during placements among students. Few faculty members felt that students wasted their time on Whatsapp which adversely affected their academic performance.

\section{Conclusion}

Rather than wasting time on gadgets, the youth can constructively engage in some value driven activities like discussion forums, quizzes and so on. These benefits can be explored not only for students but also for working professionals. There are limited studies that have been done particularly in the Indian perspective on the impact of Whatsapp on placements. This study provides some information that would be the starting point of Whatsapp messenger usage in the overall development of the students of Bschools.

\section{References}

Amry, A. B. (2014). The impact ofwhatsapp mobile social learning on the achievement and attitudes of female students compared with face to face learning in the classroom.European Scientific Journal, No.22.

Bouhnik, D. (2014). WhatsApp goes to school: Mobile instant messaging between teachers and Students. Journal of Information Technology Education Research.

Glad Mohesh MI, S. S. (2016). Perceptions on M-Learning through WhatsApp application. Journal of Education Technology in Health Sciences, 57-60. 
Johnson Y. G. D. (2014). The Impact of Whatsapp Messenger Usage on Students Performance in Tertiary Institutions in Ghana. Journal of Education and Practice, 157-164.

Joshi, T. B. (2014). A Study of Students' Experiences of Mobile Learning. Global Journal of Human-Social Science interdisciplinary.

Kavita. (2015). THE INFLUENCE OF SOCIAL MEDIA ON INDIAN. International Journal of Advance Research In Science And Engineering, 487495.

Kopung, J. N. (2016). Exploring the Use of WhatsApp in Mathematics Learning: A Case Study. J Communication, 266-273.

Mefolere, K. F. (2016). WhatsApp and Information Sharing: Prospect and Challenges. International Journal of Social Science and Humanities Research , 615-625.

Jisha K, D. J. (2014). Whatsapp: A Trend Setter in Mobile Communication among Chennai Youth. IOSR Journal of Humanities And Social Science, 01-06.

Roman, D. N. (2016). AcademiaWhatsApp Messaging: Achievements and Success in AcademiaWhatsApp Messaging: Achievements and Success in Academia WhatsApp Messaging: Achievements and SuccessWhatsApp Messaging: Achievements and Success in Academia. International Journal of Higher Education, Vol. 5, No. 4; 2016.

So, S. (2016). Mobile instant messaging support for teaching and learning in. Interet and higher eductaion, 32-42.

Susilo, A. (2014). Exploring Facebook and Whatsapp As Supporting Social Network Applications For English Learning In Higher Education. 1024 